\title{
Status of Asiatic Golden Cat Catopuma temminckil Vigors \& HoRSFIELD, 1827 (CARNIVORA: FELIDAE) IN BHUTAN
}

ISSN 0974-7907 (Online) ISSN 0974-7893 (Print)

\section{OPEN ACCESS}

Tashi Dhendup

Ugyen Wangchuck Institute for Conservation and Environment, Department of Forest and Park Services, Ministry of Agriculture and Forests, Royal Government of Bhutan, Lamai Goempa, Bumthang Bhutan 32001 tashid@uwice.gov.bt

\section{(c) (1)}

Abstract: The Asiatic Golden Cat is a Near Threatened wild cat species as listed by the IUCN. Being a lesser studied species, there is a general paucity of data and hence, global assessment of its true status has been very difficult. In Bhutan, available information on this species is mainly from biodiversity surveys on big mammals such as Tiger and Snow Leopard. A modest attempt has been made to review all available literature on Asiatic Golden Cat in Bhutan and abroad to describe the current status of the species in the country and the need for further studies.

Keywords: Catopuma temminckii, conservation, distribution, habitat, morphs, threats.

DOI: http://dx.doi.org/10.11609/jott.2560.8.4.8698-8702 | ZooBank: urn:Isid:zoobank.org:pub:BE23AFB9-2227-4F68-9F98-7030D996B77A

Editor: Anonymity requested.

Date of publication: 26 April 2016 (online \& print)

Manuscript details: Ms \# 2560 | Received 18 February 2016 | Final received 28 March 2016 | Finally accepted 05 April 2016

Citation: Dhendup, T. (2016). Status of Asiatic Golden Cat Catopuma temminckii Vigors \& Horsfield, 1827 (Carnivora: Felidae) in Bhutan. Journal of Threatened Taxa 8(4): 8698-8702; http://dx.doi.org/10.11609/jott.2560.8.4.8698-8702

Copyright: (c) Dhendup 2016. Creative Commons Attribution 4.0 International License. JoTT allows unrestricted use of this article in any medium, reproduction and distribution by providing adequate credit to the authors and the source of publication.

Funding: None.

Conflict of Interest: The author declares no competing interests.

Author Details: TASHI DHENDUP works as a Research Officer at the Ugyen Wangchuck Institute for Conservation and Environment under the Department of Forest and Park Services, Royal Government of Bhutan. He is interested in conservation biology and works to infuse research and conservation in Bhutan. His main research areas include wild cats' community studies and assessments of poaching and other threats to wildlife and habitats. He is Bhutans first National Geographic Young Explorer and is currently working on clouded leopards.

Acknowledgements: I would like to thank Sangay Pelzang, ICT Officer at UWICE for helping me with the map and also Mr. Yeshi Tshering, Forestry Officer, Phrumsengla National Park, Bhutan for sharing pictures of the Asiatic Golden Cat. 


\section{INTRODUCTION}

In spite of the fact that Bhutan is perceived as a feature of most biodiversity protection need systems, couple of endeavors have been made to record the nation's biodiversity. These efforts have detected mostly common and large mammals like Tiger Panthera tigris, Snow Leopard Panthera uncia, Elephant Elephas maximus, but have excluded rare and elusive species such as Clouded Leopard Neofelis nebulosa, Asiatic Golden Cat Catopuma temminckii, Marbled Cat Pardofelis marmorata, Fishing Cat Prionailurus viverrinus and Jungle Cat Felis chaus (Tempa et al. 2013). Bhutan is one of the top 10 global hotspots for biodiversity that include the 'Himalayan' hotspot (Gillison 2012) and is home to 11 wild cat species, of which, six are small cats (Wangchuk et al. 2004). In spite of the knowledge of wild cats playing an important role in forest ecosystems, such as regulating mammal and bird populations (Beschta \& Ripple 2009; Appel et al. 2012), there are almost no published studies on small wild cats in Bhutan, clearly indicating a paucity of information on basic ecology of these species in this region. Of the diversity of lesser known wild cat species in Bhutan, the Asiatic Golden Cat as "a feline of many costumes" is garnering much interest among Bhutanese researchers.

The Asiatic Golden Cat, also known as Temmincks Cat, is a medium-sized wild cat and is the largest of the small group of oriental felines with the exception of Clouded Leopard Neofelis nebulosa (Bashir et al. 2011). This species is listed as "Near Threatened" in the IUCN Red List and is also an Appendix I species as listed by CITES. There is still a lack of reliable estimates on the density of this species across its range, however, it is estimated that its populations are declining (McCarthy et al. 2015).

\section{Distribution}

The Asiatic Golden Cat ranges in South and Southeast Asia, from Nepal and parts of China to peninsular Malaysia and Sumatra (Lyngdoh et al. 2011).
Its distribution status is yet to be completed decided in some countries including Bhutan (Kawanishi \& Sunquist 2008). Photographic evidence on the presence of this cat in the higher hills of eastern Himalaya were reported only recently. The species was first camera-trapped in Nepal in 2009 (Ghimirey \& Pal 2009), in the northeastern Indian states of Arunachal Pradesh and Sikkim in 2010 (Lyngdoh et al. 2011) and 2009-2010 (Bashir et al. 2011) respectively. There is very little information published on the cat and it is rarely seen in the wild (Jutzeler et al. 2010). However, a recent increase in records was observed from camera-trap studies (J. Sanderson pers. comm. in Jutzeler et al. 2010). Some surveys have recorded the cat more frequently than sympatric wild cats (Lyngdoh et al. 2011; Gumal et al. 2014; Pusparani et al. 2014), while others have recorded it less frequently (Lyngdoh et al. 2011; Tempa et al. 2013). This information may suggest that their abundance, relative to other species, likely varies significantly across their range in South Asia (McCarthy et al. 2015) and warrants further investigation. Increasing camera-trap surveys in Bhutan are recording further detection of the species (Jigme 2011; Tempa et al. 2011, 2013; Thinley et al. 2015b). The Asiatic Golden Cat has been recorded from the southern foothills of Royal Manas National Park at elevations of $80 \mathrm{~m}$ (Tempa et al. 2011, 2013) to Jigme Dorji National Park at an elevation of $4033 \mathrm{~m}$ (Jigme 2011) (Table 1). It has also been recorded in seven protected areas: Jigme Khesar Strict Nature Reserve (DoFPS 2011), Jigme Dorji National Park (Jigme 2011; DoFPS 2015; Thinley et al. 2015a), Jigme Singye Wangchuck National Park (Wang 2007), Phibsoo Wildlife Sanctuary (DoFPS 2012a), Thrumshingla National Park (DoFPS 2008), Wangchuck Centennial National Park (DoFPS 2012b), Royal Manas National Park (Jigme 2011; Tempa et al. 2011, 2013; DoFPS 2015), and two districts outside of the protected areas: Trongsa and Wangdue Phodrang (Jigme 2011). However, the species has not been recorded from areas in eastern Bhutan such as Bumdeling Wildlife Sanctuary and Sakteng Wildlife Sanctuary (Fig. 1). All of this information has been derived from bycatch camera trap images and

Table 1. Published altitudinal records of Asiatic Golden Cats in Bhutan

\begin{tabular}{|c|c|l|l|l|}
\hline & Elevations $(\mathbf{m})$ & Area & Region & Source \\
\hline 1 & 3738 & Jigme Singye Wangchuck National Park & Central Bhutan & Wang 2007 \\
\hline 2 & 4033 & Jigme Dorji National Park & Northern Bhutan & Jigme 2011 \\
\hline 3 & $2985-3900$ & Ugyen Wangchuck Institute Research Preserve & Central Bhutan & Vernes et al. 2015 \\
\hline 4 & $3488-3810$ & Jigme Dorji National Park & Northern Bhutan & Thinley et al. 2015 \\
\hline 5 & $80-2900$ & Royal Manas National Park & Southern Bhutan & Tempa et al. 2011, 2013 \\
\hline
\end{tabular}




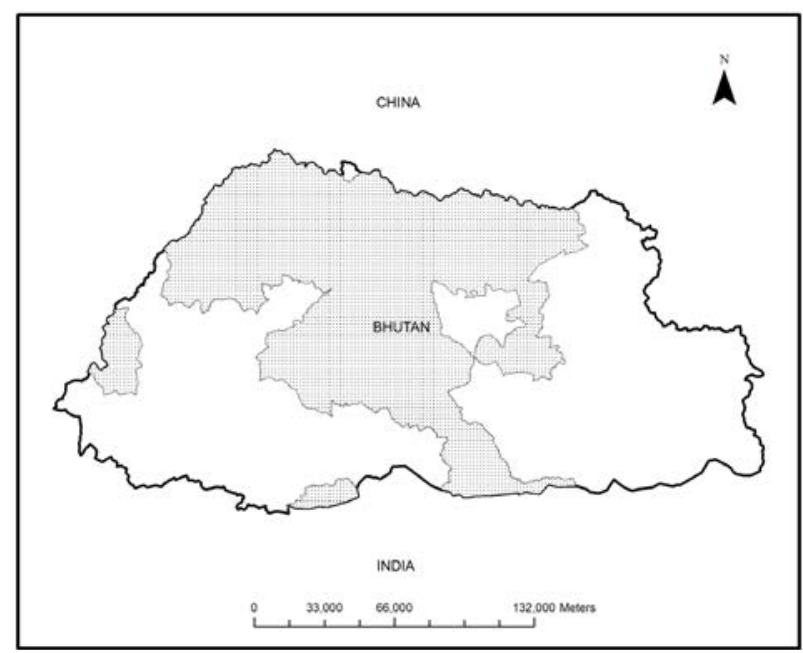

Figure 1. Current distribution of Asiatic Golden Cat in Bhutan

hence a more research focused study is recommended to understand the true status of its distribution in Bhutan.

\section{Habitats}

We speculate that the Asiatic Golden Cat is a habitat generalist as it does not show any significant preference for a particular habitat. It is known to occur in multiple types of forested areas, "including dry deciduous forest, evergreen forest and tropical rainforest", and additionally in moderately open living spaces, such as shrubs and grasslands (Lyngdoh et al. 2011).

In Bhutan, Asiatic Golden Cats were believed to inhabit tropical and sub-tropical moist evergreen and dry deciduous forest, and also open habitats (Wangchuk et al. 2004). Recent records have reported their presence in areas of dwarf rhododendron forest and grasslands at high elevations (Wang 2007), in conifer forests dominated by Fir Tsuga dumosa (Vernes et al. 2015), and also in cool broadleaf and mixed-conifer forests (Thinley et al. 2015b). Tempa et al. (2013) reported the species from Royal Manas National Park where the vegetation is mainly dominated by warm broad-leaved forests.

\section{Ecology and behaviour}

Much remains to be learned about the ecology and behaviour of the Asiatic Golden Cat. Information from two radio-collared individuals in Thailand showed diurnal and crepuscular activity patterns suggesting that the species is not principally nighttime as previously thought (Grassman et al. 2005). Similar diurnal and crepuscular activity patterns were also observed in Bhutan (Jigme 2011, Thinley et al. 2015b; Vernes et al. 2015). It exhibited maximum activity from mid morning to late evening with activities peaking at twilight (Vernes et al. 2015).

In a study from Jigme Dorji National Park (Thinley et al. 2015b), the Golden Cat was the most photographed wild cat with a Relative Abundance Index (RAI) of 0.80 . Among all the wild cats recorded in the study area, that included Tiger, Leopard, Marbled Cat, Clouded Leopard and Leopard Cat, the Asiatic Golden Cat along with the Tiger appeared to have the widest spatial coverage and their occupancy was found to be twice as high in fall than during winter. However, both species did not exhibit any seasonal patterns of occurrence during the study period.

\section{Morphs}

The Asiatic Golden Cat is remarkably polymorphic in its pelage and there are four morphs known to science: common morph, grey morph, melanistic morph and spotted morph (McCarthy et al. 2015). All these four morphs have been reported in Bhutan. The most widely recognized body shading is fox-red to brilliant chestnut, yet it can likewise be darkbrown, pale cinnamon, splendid red, or dim with incidental melanistic frames (Ghimirey \& Pal 2009; Jutzeler et al. 2010). The ocelot morph was previously known only from China (Wang \& Macdonald 2009).

The rare ocelot morph was first recorded in Bhutan in 2007 in Jigme Singye Wangchuck National Park at $3738 m$ (Wang 2007), and in the following years, was also recorded in central and eastern Bhutan. The golden form has been recorded at altitudes between $1500 \mathrm{~m}$ and $2500 \mathrm{~m}$, while the grey and spotted morphs were photographed only above 3600m (Jigme 2011). These records suggest a possible selection for specific morphs at different altitudes, perhaps as a response to changing vegetation cover with altitude (Sangay et al. 2014). However, in a study in central Bhutan, all morphs were recorded at the same locality (Vernes et al. 2015). Grey, spotted and golden morphs were photographed at the same camera trap location and on two occasions, spotted and golden individuals were found to be socially interacting. Similarly, a common morph and a grey morph were also recorded in the same locality in Phrumsengla National Park (Yeshi Tshering pers. comm.) (Images 1, 2). There is still a need for research to obtain further data on the occurrence of different colour morphs at different altitudes and in different forest types to determine whether any biogeographic patterns exist (Vernes et al. 2015).

\section{Threats}

Being primarily a forest-dependent species, the 


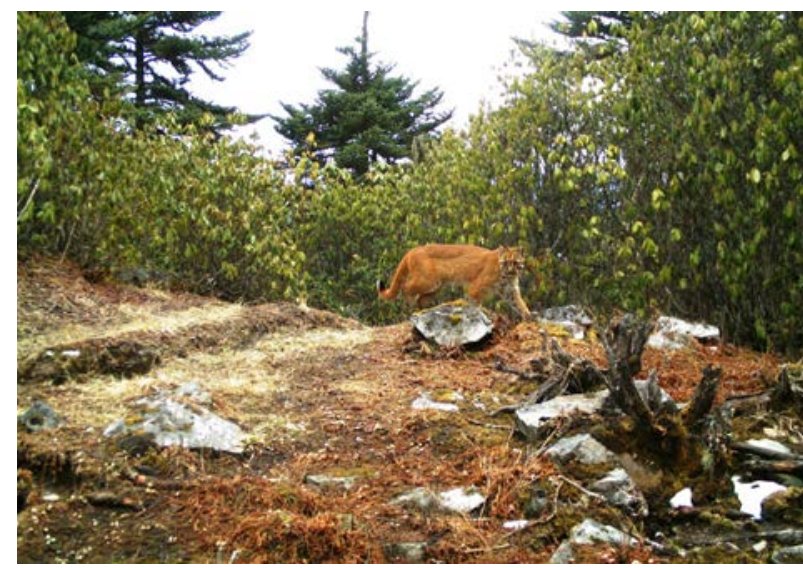

Image 1. Asiatic Golden Cat in Phrumsengla National Park, Central Bhutan (@ Phrumsengla National Park)

Asiatic Golden Cat is threatened by habitat loss and habitat fragmentation across its range (McCarthy et al. 2015). It is also threatened by indiscriminate snaring (Holden 2001) and hence poaching is also a significant concern. Asiatic Golden Cat is reported to have killed livestock, including not only poultry, but also larger animals such as sheep, goats, buffalo calves and other ungulates (Sunquist \& Sunquist 2002). In Bhutan, there is no record of livestock depredation by Asiatic Golden Cat. In the last two years, forest officials reported a single case of skin trade of Asiatic Golden Cat and that too, of the rare ocelot morph (DoFPS 2015). However, a huge number of snares targeted towards musk deer and pheasants have been reported in both protected and territorial division forests, hence the Asiatic Golden Cat could be threatened with unintentional and undirected snaring. A declining ungulate abundance in many parts of Southeast Asia has also been observed as a threat (Sanderson et al. 2008). Fortunately, Bhutan has more than $60 \%$ of its area under forest cover and an overwhelming $51.4 \%$ of the country is under protected areas. However, with the increase in hydropower projects and other developmental activities, land conversion could be a potential threat to many species here (McCarthy et al. 2015). Clearly, the information on threats is scarce and understanding threats based on more focussed research is needed to devise a conservation strategy for the species (Kawanishi \& Sunquist 2008).

\section{Conservation actions and research needs}

It was reported that there is no legal protection for the Asiatic Golden Cat outside protected areas in Bhutan (Nowell \& Jackson 1996). Although the species does not receive special legal attention as is the case for the Tiger,

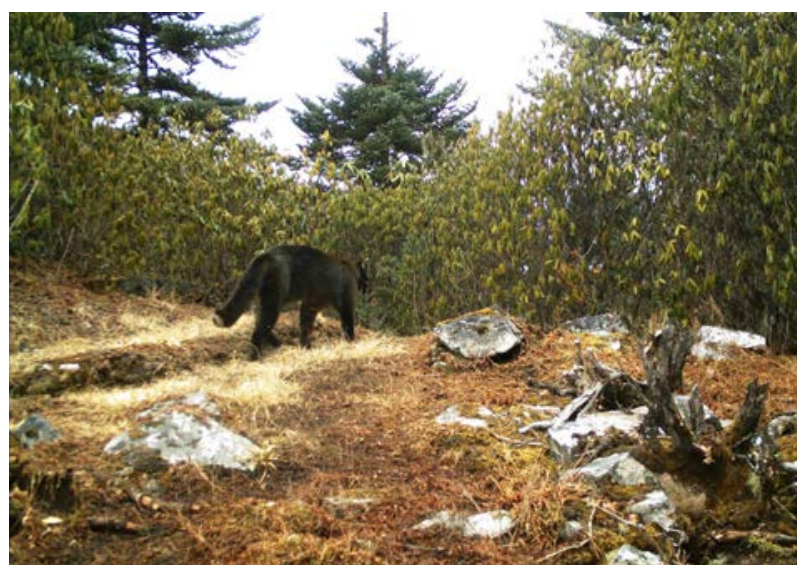

Image 2. Melanistic Asiatic Golden Cat in the same location in Phrumsengla National Park (@ Phrumsengla National Park)

Snow Leopard and Clouded Leopard, the enactment of the Forest and Nature Conservation Act of 1995, and Forest and Nature Conservation Rules 2006 have enforced regulations outside protected areas as well. Poaching in government reserve forests and protected areas could result in penalties similar to poaching any other wild animal. In addition, a fine for confiscation of a small cat's skin amounts to around USD 30 per piece. Hence, it is a legally protected species in Bhutan (Jigme 2011).

No studies have been targeted on the Asiatic Golden Cat in Bhutan and the data which are currently available are mainly bycatch camera trap images from Tiger and biodiversity surveys. Research on the nature of the species is exceptionally prescribed keeping in mind the end goal to comprehend populace patterns and actualize compelling protection methodologies (McCarthy et al. 2015). For effective conservation and management of predatory felids, information on the population status, movement patterns, diet, habitat requirements and demography as well as population status and ecology of prey species is required (Grassman et al. 2005). A lack of reliable density estimates is also observed to be severely limiting the process to accurately assess its true status across its range and uncertainties still remain in assessing the future of the species (McCarthy et al. 2015). Besides the lack of information on animal numbers, information on relative abundance, activity patterns and habitat types is also considered to be a major impediment to scientific management of animals and habit conservation (Balmford et al. 2005). Research on the Asiatic Golden Cat in Bhutan is recommended with focus on the following:

1. Populations status and trends;

2. Spatial and temporal activity patterns; 
3. Distribution, habitat occupancy and habitat associations;

4. Identification and documentation of known and possible threats to the Asiatic Golden Cats and their prey species.

Department of Forest and Park Services (DoFPS), Bhutan is planning to radio-collar a few individuals within the next few years to study their movement in the Bhutan Himalaya. Apart from this, the department is also planning to map the distribution of the Asiatic Golden Cat from the recent nationwide Tiger survey camera trap data. As of now, more information from various sources needs to be gathered to determine the true conservation status of the species in Bhutan. It is recommended that wildlife researchers across the range of the Asiatic Golden Cat collaborate to share and combine their data to further unravel the ecology and behavior of the species (Vernes et al. 2015).

\section{REFERENCES}

Appel, A., Y. Ghimirey \& R. Acharya (2012). Status assessment of wild felids with a special focus on clouded leopard and Asian Golden Cat in the Hugu-Kori forest, Annapurna Conservation Area, Nepal. Friends of Nature, Kathmandu, Nepal, 24pp.

Balmford, A., P. Crane, A.P. Dobson, R.E. Green \& G.M. Mace (2005). The 2010 challenge: data availability, information needs and extraterrestrial insights. Philosophical Transactions of the Royal Society of London, Series B 360: 221-228; http://dx.doi.org/10.1098/ rstb.2004.1599

Bashir, T., T. Bhattacharya, K. Poudyel \& S. Sathyakumar (2011). Notable observations on the melanistic Asiatic Golden Cat (Pardofelis temminckii) of Sikkim, India. NeBio 2(1): 1-4.

Beschta, R.L. \& W.J. Ripple (2009). Large predators and trophic cascades in terrestrial ecosystems of the western United States. Biological Conservation 142: 2401-2414; http://dx.doi.org/10.1016/j. biocon.2009.06.015

DoFPS (2008). Thrumshingla Management Plan July 2008 - June 2018. Department of Forests and Park Services, Ministry of Agriculture and Forests, Royal Government of Bhutan.

DoFPS (2011). Toorsa Strict Nature Reserve Management Plan 2012-2017. Department of Forests and Park Services, Ministry of Agriculture and Forests, Royal Government of Bhutan.

DoFPS (2012a). Conservation Management Plan Phibsoo Wildlife Sanctuary July 2012 - June 2017. Department of Forest and Park Services, Ministry of Agriculture and Forests, Royal Government of Bhutan.

DoFPS (2012b). Conservation Management Plan Wangchuck Centennia National Park July 2012 - June 2017. Department of Forest and Park Services, Ministry of Agriculture and Forests, Royal Government of Bhutan.

DoFPS (2013). Bumdeling Wildlife Conservation Management Plan July 2013 - June 2018. Department of Forests and Park Services, Ministry of Agriculture and Forests, Royal Government of Bhutan.

DoFPS (2015). Wildlife Products and Red Sander Seizures in 2013 and 2014. Department of Forest and Park Services, Royal Government of Bhutan.

Ghimirey, Y. \& P. Pal (2009). First camera trap image of Asiatic Golden Cat in Nepal. Cat News 51:19.

Gillison, A. (2012). Biodiversity in Bhutan: A preliminary synthesis. Center for Biodiversity Management, 1pp. http://biodiversity.bt/ biodiv/content/documents/document-f4cfe3a2-b846-4cf8-bd98- 24d622951046/647.pdf. Downloaded on 14 February 2016.

Grassman Jr, L.I., M.E. Tewes, N.J. Silvy \& K.J. Kreetiyutanont (2005). Ecology of three sympatric felids in a mixed evergreen forest in northcentral Thailand. Journal of Mammology 86(1): 29-38.

Gumal, M., A.B.B.M. Salleh, M.N. Yasak, L.S. Horing, B.P.Y-H. Lee, L.C. Pheng, H. Hamzah., D. Kong, D. Magintan, D.T.C. Yung, A.Z.B. Zalaluddin, A.B. Azmi, N.B. Khalid, T.P. Yen, V. Mufeng, F.C.F.M. Meng \& S. NG (2014). Small-medium wild cats of Endau Rompin Landscape in Johor, Peninsular Malaysia. Cat News Special Issue 8: 10-18.

Holden, J. (2001). Small Cats in KerinciSeblat National Park, Sumatra, Indonesia. Cat News 35: 11-14.

Jigme, K. (2011). Four Colour Morphs of and the Altitudinal Record of Asiatic Golden Cat in Bhutan. Cat News 55: 12-13.

Jutzeler, E., Y. Xie \& K. Vogt (2010). Asiatic Golden Cat in China. Cat News Special Issue 5: 40-41.

Kawanishi, K. \& M.E. Sunquist (2008). Food habits and activity patterns of the Asiatic Golden Cat (Catopuma temminckii) and Dhole (Cuon alpinus) in a primary rainforest of Peninsular Malaysia. Mammal Study 33: 173-177.

Lyngdoh, S., K.M. Selvan, G.V. Gop \& B. Habib (2011). First photographic evidences of two rare cats from Pakke Tiger Reserve, western Arunachal Pradesh. Current Science 101: 1284-1286.

McCarthy, J., S. Dahal, T. Dhendup, T.N.E. Gray, S. Mukherjee, H. Rahman, P. Riordan, N. Boontua \& D. Wilcox (2015). Catopuma temminckii. The IUCN Red List of Threatened Species 2015: e.T4038A50651004. Downloaded on 01 April 2016; http://dx.doi. org/10.2305/IUCN.UK.2015-4.RLTS.T4038A50651004.en

Nowell, K. \& P. Jackson (1996). Wild Cats Status Survey and Conservation Action Plan. IUCN/SSC Cat Specialist Group, xxiv+382pp.

Pusparani, W., H. Wibisono, G.V. Reddy, Tarmizi \& P. Bharata (2014). Small and medium sized cats in Gunung Leuser National Park, Sumatra, Indonesia. Cat News Special Issue 8: 4-9.

Sanderson, J., S. Mukherjee, A. Wilting, S. Sunarto, A. Hearn, J. Ross \& J.A. Khan (2008). Pardofelis temminckii. In: IUCN 2010. 2010 IUCN Red List of Threatened Species. Downloaded on 16 January 2010.

Sangay, T., R. Rajaratnam \& K. Vernes (2014). Wildife camera trapping in the Himalayan kingdom of Bhutan with recommendations for the future, pp. 87-98. In: Meek, P. \& P. Fleming (eds.). Camera Trapping for Animal Monitoring. CSIRO Publishing, Collingwood.

Sunquist, M.E. \& F. Sunquist (2002). Wild Cats of the World. University of Chicago Press, Chicago, Illinois, 53-56pp.

Tempa, T., N. Norbu, P. Dendup \& T. Nidup (2011). Results from a Camera Trapping Exercise for Estimating Tiger Population Size in the Lower Foothills of Royal Manas National Park. UWICE Press, 18pp.

Tempa, T., M. Hebblewhite, L.S. Mills, T.R. Wangchuk, N. Norbu, T. Wangchuk, T. Nidup, P. Dhendup, D. Wangchuk, Y. Wangdi \& T. Dorji (2013). Royal Manas National Park: A hotspot for wild felids, Bhutan. Fauna \& Flora International, Oryx 47(2): 207-210.

Thinley, P., L. Tharchen \& R. Dorji (2015a). Conservation Management Plan of JigmeDorji National Park for the period January 2015December 2019: Biodiversity Conservation in Pursuit of Gross National happiness. Department of Forest and Park Services, Thimphu Bhutan.

Thinley, P., S.J. Morreale, P.D. Curtis, J.P. Lassoie, T. Dorji, Leki, S. Phuntsho \& N. Dorji (2015b). Diversity, occupancy, and spatiotemporal occurrences of mammalian predators in Bhutan's Jigme Dorji National Park. Bhutan Journal of Natural Resources \& Development 2(1): 19-27.

Vernes, K., T. Sangay, R. Rajaratnam \& R. Singye (2015). Social Interaction and co-occurrence of colour morphs of the Asiatic Golden Cat, Bhutan. Cat News 62: 18-20.

Wang, S.W. (2007). A rare morph of the Asiatic Golden Cat in Bhutan's Jigme Singye Wangchuck National Park. Cat News 47: 27-28.

Wang, S.W. \& D.W. Macdonald (2009). The use of camera traps for estimating Tiger and Leopard populations in the high altitude mountains of Bhutan. Biological Conservation 142: 606-613.

Wangchuk, T., P. Thinley, K. Tshering, C. Tshering, D. Yonten \& B. Pema (2004). Field Guide to the Mammals of Bhutan. Royal Government of Bhutan, 59-60pp. 